\title{
Competências constitucionais do sistema federativo envolvendo funções públicas de interesse comum em regiões metropolitanas
}

\author{
Federative system's constitutional competences involving public functions of \\ common interest in metropolitan regions
Compétences constitutionnels del système fédératif impliquant fonctions publiques d'interet commun dans la region metropolitaine
Competencias constitucionales del sistema de federaciones que implica en funciones públicas de interés común en la región metropolitana

Paulo Sérgio Mendes César ${ }^{1}$

\author{
Recebido em 30/11/2016; revisado e aprovado em 26/04/2017; aceito em 01/05/2017 \\ DOI: http://dx.doi.org/10.20435/inter.v18i3.1447
}

\begin{abstract}
Resumo: No contexto federativo brasileiro, mostra-se pertinente o aprofundamento das competências das administrações públicas municipais metropolitanas e de estados federados no tocante à gestão das funções públicas de interesse comum. Analisa-se o marco regulatório dessas funções públicas e a necessidade de mudanças salutares para as administrações públicas municipais e para os estados federados.

Palavras-chave: Constituição Federal de 1988; Estatuto da Metrópole; funções públicas de interesse comum; região metropolitana.
\end{abstract}

\begin{abstract}
In the brazilian federative context, it is pertinent developing the skills of the metropolitan municipal government and federal states regarding the management of public functions of common interest. It analyzes the regulatory framework of these public functions and the need to salutary changes to the municipal government and the federal states.
\end{abstract}

Key words: Federal Constitution 1988; Statute of Metropolis; public functions of common interest; metropolitan area.

Résumé: Dans le contexte fédératif brésilien, il est pertinent de développer les compétences de l'administration municipale métropolitaine et les États fédéraux en ce qui concerne la gestion des fonctions publiques d'intérêt commun. II analyse le cadre réglementaire de ces fonctions publiques et la nécessité de changements salutaires à l'administration municipale et les États fédéraux

Mots-clés: Constitution Fédérale de 1988; Le Statut de Metropolis; les fonctions publiques d'intérêt commun; la région métropolitaine.

Resumen: En el contexto federativo brasileño, es pertinente el desarrollo de las habilidades del gobierno municipal metropolitana y estados federales con respecto a la gestión de las funciones públicas de interés común. Se analiza el marco regulatorio de estas funciones públicas y la necesidad de cambios saludables en el gobierno municipal y los estados federales.

Palabras clave: Constitución Federal de 1988; Estatuto de Metrópoli; funciones públicas de interés común; área metropolitana.

\section{INTRODUÇÃO}

No sistema federativo brasileiro, existe consenso de que as funções públicas municipais se apresentam de forma distinta em regiões metropolitanas. Visando aprofundar o assunto, pretende-se um estudo acerca das funções públicas de interesse comum (FPIC) dos estados de São Paulo, Rio de Janeiro e Minas Gerais, quanto a sua aplicação, caracterização e suas peculiaridades.

\footnotetext{
${ }^{1}$ Universidade Federal de Minas Gerais (UFMG), Belo Horizonte, Minas Gerais, Brasil.
} 
Para tanto, faz-se necessário, inicialmente, explicar a natureza jurídica das regiões metropolitanas no modelo de federalismo adotado no Brasil, bem como as implicações desse modelo na prática e uma ligeira contextualização do surgimento dessa figura em nosso ordenamento.

A questão das regiões metropolitanas ainda se revela muito importante. Tendo em vista o atual quadro de escassez de recursos públicos que permeia grande parcela das administrações públicas brasileiras, a discussão acerca da titularidade para a prestação de serviços públicos nas regiões metropolitanas se apresenta cercada de conflitos de competências de origem constitucional.

Nesse desiderato, o esclarecimento do conceito das funções de natureza pública municipal e como a função de interesse comum é carente de tratamento diferenciado, isso ganha destaque no contexto de região metropolitana. Nessa linha, pode-se inferir com base em Silva (2004) que a principal atribuição de uma região metropolitana é a função pública de interesse comum, compartilhada por mais de um município.

A despeito da legislação pertinente, faz-se oportuno demonstrar como as leis acerca das FPICs em geral são omissas no tocante às situações das regiões metropolitanas, o que acaba por obrigar outras formas de pactuação e outros mecanismos de gestão compartilhada visando ao desenvolvimento regional.

\section{SISTEMA FEDERATIVO E REGIÕES METROPOLITANAS}

Oliveira (2007) e Freitas (2008) esclarecem que um país pode organizar politicamente seu território como Estado unitário, com decisões político-econômicas oriundas de um poder central, ou como Estado federativo, com certa autonomia e competência para legislar sobre assuntos de seu interesse. Os autores ainda defendem que o federalismo expressa um pacto entre forças e interesses divergentes que só pode ser mantido em um regime democrático.

Costa (2004 apud GUIMARÃES, 2010) expõe que o modelo federalista foi consagrado com a Constituição Norte-americana de 1787 e trazia a combinação do princípio da representação popular com uma dupla divisão do poder, podendo ser entendido como uma forma peculiar de organização do Estado, em que coexistem diferentes esferas territoriais dotadas de poder e autonomia. Para a autora, essa autonomia pressupõe para os governos subnacionais capacidade de auto-organização, com poderes legislativos próprios, e de autogoverno, com organização própria e eleição de seus representantes, além da capacidade de autoadministração, com organização e prestação de serviços públicos.

A Constituição da República de 1988 (CR/88) adotou o federalismo cooperativo como forma de organização do Estado brasileiro. Dessa feita, o art. 18 da CR/88 determina que a organização político-administrativa da República Federativa do Brasil compreende a União, os Estados, o Distrito Federal e os Municípios, todos autônomos.

Já as regiões metropolitanas são conceituadas como um grande centro populacional, em que uma cidade central bem desenvolvida exerce forte influência sobre as cidades vizinhas (MEIRELLES, 1993). Necessário destacar aqui que, apesar de, em geral, haver conurbação² entre os municípios metropolitanos, tal característica não é regra, bastando haver a forte influência da cidade central sobre as adjacentes. Essa influência fica evidenciada não só pela forte integração econômica dos municípios, mas também pela integração política, social e cultural.

\footnotetext{
${ }^{2}$ Área limítrofe urbanizada entre cidades, a qual faz com que muitas vezes as cidades percam seus limites físicos entre si.
} 
Saboia (1998) compreende por região metropolitana todos aqueles municípios no entorno da grande cidade, formando junto dela uma grande unidade socioeconômica. Essa unidade teria serviços urbanos e interurbanos que deixam de ser de exclusivo interesse local por estarem vinculados à metrópole.

É pacífico que não existe um quarto ente federativo no modelo brasileiro, o ente metropolitano. A estrutura da República Federativa do Brasil divide-se em União, Unidades da Federação ou Estados Federados e Municípios, cada qual com sua competência constitucional específica.

Horta (1975) destaca que as regiões metropolitanas não podem se converter em entidade de governo ou circunscrição político-administrativa. Seguindo a mesma linha, Temer (1998) reforça que as regiões metropolitanas não são "dotadas de personalidade" e acrescenta que "[...] fica afastada a ideia de governo próprio ou, mesmo, de administração própria. Não é pessoa política nem administrativa. Não é centro personalizado. Não é organismo. É órgão".

Lustosa (2010) defende que a despeito de não constituir unidade federativa, a região metropolitana é vista como um problema político, econômico e social. Afinal, o crescimento, a produção de riquezas e a população estão cada vez mais concentrados nas metrópoles, onde os problemas sociais e urbanos se acumulam.

Por essa razão, a Constituição dos Estados Unidos do Brasil, de 10 de novembro de 1937, já permitia, em seu art. 29 transcrito abaixo, o agrupamento de municípios da mesma região visando à melhor gestão dos serviços públicos comuns:

Art 29 - Os Municípios da mesma região podem agrupar-se para a instalação, exploração e administração de serviços públicos comuns. O agrupamento, assim constituído, será dotado de personalidade jurídica limitada a seus fins.

Parágrafo único- Caberá aos Estados regular as condições em que tais agrupamentos poderão constituir-se, bem como a forma, de sua administração. (BRASIL, 2937).

De acordo com Horta (1975), o surgimento das regiões metropolitanas constituiu uma novidade no Direito Constitucional brasileiro. Segundo o autor, o fundamento constitucional da região metropolitana reside, exclusivamente, na realização de serviços comuns a seus municípios integrantes.

É com a Constituição da República Federativa do Brasil de 1967 que fica determinada a necessidade de lei complementar para criação das regiões metropolitanas:

$\S 10$ - A União, mediante lei complementar, poderá estabelecer regiões metropolitanas, constituídas por Municípios que, independentemente de sua vinculação administrativa, integrem a mesma comunidade sócio-econômica, visando à realização de serviços de interesse comum. (BRASIL, 1967).

Posteriormente, através do art. 164 da Emenda Constitucional n. 01 de 1969, ficou previsto que a União, mediante lei complementar, poderia, para a realização de serviços comuns, estabelecer regiões metropolitanas constituídas por municípios que, independentemente de sua vinculação administrativa, fizessem parte da mesma região socioeconômica.

Destarte, as primeiras regiões metropolitanas brasileiras foram instituídas pela Lei Complementar n. 14, de 8 de junho de 1973, que estabeleceu as regiões metropolitanas de São Paulo, Belo Horizonte, Porto Alegre, Recife, Salvador, Curitiba, Belém e Fortaleza. A Lei Complementar n. 14/73 permitiu a unificação da execução de serviços comuns, autorizando a 
concessão de serviços a entidades estatais, a constituição de empresas no âmbito metropolitano e ainda mediante a confecção de convênios.

A despeito da Lei Complementar n. 14/73 não atribuir receita autônoma às regiões metropolitanas, Horta (1975) aponta que essa lei assegurou preferência aos municípios metropolitanos na obtenção de recursos federais e estaduais.

A Lei Complementar Paulista n. 760, de 10 de agosto de 1994, que estabelece diretrizes para a Organização Regional do Estado de São Paulo, trouxe boa conceituação de região metropolitana, nos seguintes termos:

Artigo 3- - Considerar-se-á região metropolitana o agrupamento de municípios limítrofes, com destacada expressão nacional, a exigir planejamento integrado e ação conjunta com união permanente de esforços para a execução das funções públicas de interesse comum, dos entes públicos nela atuantes, que apresente, cumulativamente, as seguintes características:

I- elevada densidade demográfica;

II- significativa conurbação;

III- funções urbanas e regionais com alto grau de diversidade; e

IV-especialização e integração sócio-econômica. (SÃO PAULO, 1994).

Para muitos, essa primeira institucionalização das regiões metropolitanas foi imposta sobre estados e municípios pelo governo federal e vista pelos segmentos progressistas como um instrumento adicional de dominação da União, que poderia exercer um controle mais direto sobre a distribuição de recursos para estas áreas na tentativa de amortecer as tensões sociais crescentes nos principais centros urbanos do país (GUIA, 2006).

Já a $\mathrm{CR} / 88$ delega aos Estados Federados a competência para instituir regiões metropolitanas em seu art. 25, §3을

Os Estados poderão, mediante lei complementar, instituir regiões metropolitanas, aglomerações urbanas e microrregiões, constituídas por agrupamentos de municípios limítrofes, para integrar a organização, o planejamento e a execução de funções públicas de interesse comum. (BRASIL, 1988).

Portanto o texto constitucional de 1988 transferiu a responsabilidade de criar regiões metropolitanas para o âmbito estadual. Com isso, reconheceu a autonomia dos estados federados para a formulação de estratégias de gestão de seu território. Não obstante, a força do municipalismo no país se traduz na clara resistência em se priorizar a questão metropolitana, que demanda ação cooperativa por parte dos atores envolvidos (MACHADO; SOUKI; FARIA, 2007).

Sobre o tema, Santos (2007) aponta que a repartição das competências constitucionais entre os entes federativos estaria fundamentada no princípio da predominância do interesse. A autora ainda define o interesse metropolitano, como aquele que transcende interesse local, não estando territorialmente limitado ao Município, mas configurando repercussão externa a ele.

Considerando a peculiaridade da repercussão das questões extramunicipais, as regiões metropolitanas permanecem como um desafio à governabilidade no Brasil. Guia (2006) assevera que, com o fim do regime militar, apesar de essas áreas concentrarem cerca de $30 \%$ da população do país - suas demandas e problemas - tais áreas passaram a enfrentar uma nova realidade marcada no plano político, decorrente da consolidação da democracia, do exercício de novas 
formas de participação, da própria mudança na redistribuição de recursos e de responsabilidades entre os três níveis de governo, com a ênfase no municipalismo.

Naquele contexto de esvaziamento político e tributário do município e da consequente perda da sua capacidade de investimento, a Lei Federal n. 14 de 1973 garantiu que "os municípios das Regiões Metropolitanas que participarem da execução do planejamento integrado e dos serviços comuns, terão preferência na obtenção de recursos estaduais e federais".

Continua Guia (2006, p. 10):

Dispensando-lhes um tratamento homogêneo, a Lei 14 começa por impor aos municípios a participação compulsória na região, que teria como finalidade a realização dos "serviços comuns de interesse metropolitano": planejamento integrado do desenvolvimento econômico e social; saneamento básico (água, esgoto, limpeza pública); aproveitamento dos recursos hídricos e controle da poluição ambiental; produção e distribuição de gás combustível canalizado; os transportes e sistema viário; e o uso do solo. Deixam de ser considerados serviços importantes, como por exemplo, a habitação, enquanto que é incluído o gás canalizado, existente somente no Rio de Janeiro e em São Paulo. (grifo nosso).

Guia (2006), ainda assevera que, nesse momento, duas questões básicas importantes foram contempladas, o conceito de interesse comum metropolitano, formalizando no nível nacional a necessidade de enfrentamento conjunto de problemas na prestação de serviços, e a preocupação com o ordenamento do uso e da ocupação do solo nas grandes cidades.

Percebe-se que a Constituição de 1988 estabeleceu novos marcos para um acordo político institucional entre os vários atores que atuam no cenário metropolitano. Forjada numa conjuntura na qual a grande questão era a celebração de um novo pacto federativo, institucionalizaram-se mecanismos de descentralização e democratização da gestão, aumentando consideravelmente a autonomia financeira dos estados e, especialmente, dos municípios.

A questão metropolitana não era vista pela Constituinte como um issue prioritário: "Ao contrário; como a institucionalização metropolitana vigente encontrava-se profundamente atrelada ao esvaziamento dos municípios e a ranços anteriores do período militar, tudo apontava para uma não política federal em relação do tema" (GUIA, 2006). Nesse sentido, a Constituição da República de 1988 teria dado um tratamento genérico à questão das regiões metropolitanas, delegando aos estados a maioria das definições de suas atribuições, antes concentradas na União. Assim, atualmente, com a Carta Magna de 1988, sabe-se que ficou incumbido aos estados instituir ou alterar regiões metropolitanas, nos termos de lei complementar federal, ainda não editada.

\section{FUNÇÕES PÚBLICAS DE INTERESSE COMUM METROPOLITANAS}

As competências municipais são oriundas principalmente dos artigos 23 e 30 da CR/88. $\mathrm{O}$ art. 23 cuida da competência executiva comum, compartilhada por todos os entes federados enquanto o art. 30 trata das competências exclusivas dos municípios, com destaque para seu inciso $V$, que atribui ao município a organização e prestação, direta ou sob o regime de concessão ou permissão, os serviços públicos de interesse local.

Silva (2004) assevera que a repartição de competência entre os entes federados é norteada pelo princípio da predominância do interesse. De acordo com esse princípio, caberiam à União as matérias de predominante interesse geral e nacional, aos Estados caberiam os interesses regionais, e aos Municípios caberiam os interesses locais. No mesmo sentido, Meirelles (1993) 
já defendia que o interesse local não é interesse exclusivo do município, o que determina a competência sobre uma função é a predominância do interesse de um ente sobre os demais.

Conforme asseveram Moreira e Guimarães (2015), antes de 1988 a expressão utilizada para caracterizar o âmbito de competência municipal era "peculiar interesse", termo que suscitou debates doutrinários tanto para a defesa da ideia de exclusividade ou interesse privativo do município, como para afirmar que se tratava de questão relativa à predominância do interesse municipal, a ser verificada em determinados casos. Consolidado o último entendimento, tem-se que "peculiar" não equivale a "privativo" ou a "exclusivo", mas ao que é "predominante". Segundo as autoras, ainda que tenham remanescido divergências sobre o assunto, a CR/88 as sanou ao substituir a expressão "peculiar interesse" por "interesse local".

Para Barroso (2007) essa noção de predominância implica um conceito dinâmico, em que determinada atividade considerada hoje de interesse predominantemente local, com o decurso de tempo e a evolução dos fenômenos sociais, poderá perder tal natureza, passando para o âmbito de predominância regional e até mesmo para o âmbito federal. Para esse autor, fatores como o surgimento de novos conglomerados urbanos e ações em conjunto de municípios limítrofes poderiam ser causa para tal mudança de predominância.

Seguindo tal raciocínio, em casos de conflitos de competências entre os entes da Federação, deve-se observar o princípio da predominância do interesse, visto que este rege a identificação da competência dos entes federados. Como visto acima, a Constituição Federal reconhecendo a existência de peculiaridades em áreas urbanas com integração territorial e socioeconômica, permitiu aos estados federados instituir regiões metropolitanas, além de aglomerações urbanas ou microrregiões.

Vale mencionar que toda função pública de interesse comum é, em última análise, um serviço público de interesse local, ou municipal. Todavia, como citado acima, nas regiões metropolitanas tais serviços públicos ganham limitação peculiar para os municípios, tanto legalmente quanto operacionalmente.

A despeito da mitigação de conflitos através do princípio da predominância do interesse, há de se reforçar a garantia constitucional da autonomia municipal. Bulos (2011, p. 154 apud HENRIQUES FILHO, 2013) aponta que:

[...] ao lado das capacidades de autogoverno, autoadministração e autolegislação que já possuíam, o constituinte de 1988 conferiu-Ihes [aos Municípios] a capacidade de autoorganização que resulta na autonomia organizatória, que é o poder de criar lei orgânica própria, observado o modelo federal, insculpido na Carta Magna. A autonomia organizatória é uma autonomia normativa. Sem embargo, a grande mensagem que a autonomia organizatória incute em nossa mente é a seguinte: os Estados-Membros, ao contrário do regime passado, não têm ingerência sobre os Municípios. Eles podem organizar, estabelecer competências ou ditar suas estruturas, sem a chancela dos governos estaduais. Trata-se, pois, do reflexo da capacidade organizatória do Município.

Todavia, a despeito da reconhecida autonomia dos municípios brasileiros, tem-se que as funções públicas de interesse comum são tidas como aquelas atividades ou serviços de natureza pública cuja realização por parte de um município, isoladamente, seja inviável ou cause impacto nos outros Municípios integrantes de uma mesma região metropolitana. O principal objetivo da gestão das funções públicas de interesse comum é o desenvolvimento econômico e social da região metropolitana, a partilha equilibrada dos seus benefícios e a definição de políticas compensatórias dos efeitos da sua polarização. 
A titularidade de grande parte das funções públicas é relativamente pacífica, salvo quando as funções potencialmente causam impacto em outras municipalidades. Sob o prisma do Direito Público, as funções públicas de interesse comum são, a priori, funções públicas de competência municipal. Mello (1999, p. 132) conceitua competência como "o círculo compreensivo de um plexo de deveres públicos a serem satisfeitos mediante o exercício de correlatos e demarcados poderes instrumentais, legalmente conferidos para a satisfação de interesses públicos".

Eros Roberto Grau (1974, p. 17) definiu as funções metropolitanas como:

[...] atividades e serviços urbanos, ou parte destes, que, pela natureza de sua disciplina, implantação ou operação, resultem em conexões e interferências recíprocas entre os diferentes municípios, exigindo ação unificada e planejada que ultrapasse seus limites institucionais.

Ocorre que em áreas conurbadas, especialmente em regiões metropolitanas, a prestação de um serviço público por um município pode e geralmente causa impactos noutro município limítrofe. E quando surgem os conflitos no tocante à competência, mesmo que pareça uma discussão técnica restrita ao setor governamental, sempre se chega às delimitações jurídicas, especificamente do Direito Constitucional e do Direito Administrativo.

Ainda de acordo com Grau (1974, p. 19):

Se, por um lado, as atividades e serviços urbanos, nas cidades não conurbadas, são satisfatoriamente empreendidos pelas administrações locais, isoladamente, é certo também que, nas regiões metropolitanas, uma parte delas pode consubstanciar função metropolitana e outra não. É o caso, por exemplo, da função abastecimento de água, onde a captação, adução e tratamento prescindem de uma administração unificada, sendo de interesse estritamente local, porém - e podendo não merecer aquele tipo de administração - a sua distribuição ao consumo.

Nas palavras de Barroso (2007, p. 13):

Percebeu-se, com relativa facilidade, que os Municípios isoladamente não eram capazes de prestar os serviços demandados por essa enorme quantidade de pessoas que passou a viver nos grandes centros ou ao seu redor, sem qualquer preocupação específica com os limites municipais. O fato é que atender às necessidades desse contingente populacional tornou-se caro, complexo e muitas vezes tecnicamente inviável para cada Município sozinho.

A deficiência de um município tratar isoladamente uma FPIC fica tão evidente pelo fato de que inúmeras formas de pactuação são frequentemente estabelecidas. È o caso dos consórcios públicos, dos convênios, dos termos de cooperação e das parcerias. Até com a esfera privada, como ocorre nas parcerias público privadas (PPPs).

Por essa razão, Moreira e Guimarães (2015) defendem que, quando se tratar de municípios integrantes de regiões metropolitanas, sua autonomia constitucional deve ser interpretada de forma a conjugar os interesses regionais e os locais.

Importante lembrar que os processos de democratização e de descentralização oriundos da Constituição da República de 1988 deram sustentação à crença de que os municípios resolveriam sozinhos seus problemas de políticas públicas, bastando que para isso lhes fossem repassados o poder e os recursos necessários. Porém, como é sabido, os municípios encontram diversos obstáculos na gestão dos serviços públicos, e em especial com os de interesse comum a mais de um município. É nesse contexto que o papel do estado ganha destaque.

Na verdade verificou-se que a descentralização de recursos financeiros, organizacionais e políticos para os municípios produziu benefícios importantes, mas também resultou em efeitos 
perversos. Aumentou a competição fiscal e as dificuldades adicionais de coordenação interinstitucional. O planejamento metropolitano, que era visto como prática autoritária, foi deslegitimado e produziu uma agenda pública local ancorada no princípio de que todos os problemas poderiam ser resolvidos localmente, com graves prejuízos para a gestão dos serviços de interesse comum (SOUZA, 2002).

Moreira e Guimarães (2015) chamam à atenção para o fato de que, somente com a edição do Estatuto da Metrópole, Lei Federal n. 13.089, de 12 de janeiro de 2015, foram estabelecidas diretrizes gerais para o planejamento, a gestão e a execução das funções públicas de interesse comum em regiões metropolitanas e em aglomerações urbanas instituídas pelos Estados, além de normas gerais sobre o plano de desenvolvimento urbano integrado, outros instrumentos de governança interfederativa e critérios para o apoio da União a ações que envolvam governança interfederativa no campo do desenvolvimento urbano.

Além da referida reestruturação, seria muito providencial que houvesse também uma maior prática de cooperações intermunicipais e de preferência com a participação do Estado Federado.

A Carta Magna estabelece, no parágrafo único do art. 23, que "leis complementares fixarão normas para a cooperação entre a União e os Estados, o Distrito Federal e os Municípios, tendo em vista o equilíbrio do desenvolvimento e do bem-estar em âmbito nacional".

A Constituição do Estado de Minas Gerais (CEMG) elenca em seu art. 166, dentre os objetivos prioritários do município, na realização de interesses comuns, cooperar com a União e o Estado, e associar-se a outros municípios. Nesse sentido, faculta ao município ainda, em seu art. 181:

I- associar-se a outros, do mesmo complexo geoeconômico e social, mediante convênio previamente aprovado pela Câmara Municipal, para a gestão, sob planejamento, de funções públicas ou serviços de interesse comum, de forma permanente ou transitória;

II- cooperar com a União e o Estado, nos termos de convênio ou consórcio previamente aprovados pela Câmara Municipal, na execução de serviços e obras de interesse para o desenvolvimento local;

III - participar, autorizado por lei municipal, da criação de entidade intermunicipal para realização de obra, exercício de atividade ou execução de serviço específico de interesse comum. (MINAS GERAIS, 1989).

Na legislação mineira, já se encontram dispositivos nesse sentido, que contemplam instrumentos de gestão compartilhada, como consubstanciado nos parágrafos 20 e 30 do Decreto no 45.083/2009 abaixo transcritos:

$\S 2$ ㅇ A gestão das funções públicas de interesse comum se efetivará, preferencialmente, no que couber, mediante convênios de cooperação ou consórcios públicos, instrumentos do federalismo cooperativo de que trata a Lei Federal № 11.107, de 6 de abril de 2005.

§ 3 A Agência RMBH apoiará tecnicamente a formalização de mecanismos institucionais voluntários de gestão metropolitana, notadamente os convênios de cooperação e os consórcios públicos.

Medauar e Oliveira (2006 apud CÉSAR, 2008), destaca que os consórcios públicos são resultado de livre associação de entes federados, para atender objetivos comuns dos entes consorciados. As atividades desenvolvidas em sua área de atuação correspondem ao território desses entes. Esse espaço é denominado "espaço interfederativo". 
Convém ressaltar que os consórcios públicos são instrumentos de objetivos específicos, como destinação de resíduos sólidos e atendimento à saúde, mas que não se confundem ou ganham a dimensão da gestão metropolitana. Essa tem gargalos bem maiores, fruto do presente trabalho.

Mas de pouco adianta alterar a legislação estadual se nos municípios não ocorrer mudança de paradigmas. Para isso, seria muito importante haver também um intenso processo de capacitação técnica dos servidores municipais, passo que investir no capital humano traria retornos na eficiência das administrações públicas municipais.

Fernandes e Pereira (2009) destacam como aspecto importante, além da contínua profissionalização da administração pública, o gerenciamento de programas, especialmente, no que diz respeito às políticas urbanas, por meio da formação e contratação de "gerentes das cidades". Pois acreditam que a solidez técnica dos gestores públicos assegura não apenas a racionalidade administrativa e financeira, mas também, a qualidade do processo de formulação e avaliação das políticas públicas e, consequentemente, a sustentabilidade das políticas públicas municipais.

A necessidade da administração pública brasileira em geral, readequar-se ao modelo metropolitano é item latente, que exige urgentemente, maior atenção dos agentes políticos que pautam as decisões governamentais. Corroborando com este argumento, tramita no Supremo Tribunal Federal a Ação Direta de Inconstitucionalidade (ADI) n $1.842^{3}$, que discute qual ente tem responsabilidade de atender ao saneamento básico nos casos de aglutinações urbanas.

A questão é polêmica e divide o STF. Segundo o ministro Gilmar Mendes, em regiões metropolitanas, o poder decisório não deveria ser transferido integralmente para o estado federado, como entendia o ministro Maurício Corrêa, bem como não deveria permanecer em cada município individualmente, como sustentava o ministro Nelson Jobim.

Na ADI em tela, o ministro Gilmar Mendes defende que a função pública de saneamento frequentemente extrapola o interesse local e passa a ter natureza de interesse comum "apta a ensejar a instituição de regiões metropolitanas, aglomerações urbanas e microrregiões nos termos do artigo 25, parágrafo 3ำ, da Constituição Federal”. Mas entende ser inadmissível a transferência integral do poder concedente, seja ao estado federado ou ao município. Isto porque "tal fato eliminaria, neste aspecto, a capacidade de autoadministração dos municípios envolvidos e consequentemente núcleo essencial da autonomia municipal".

Assevera o ministro Gilmar Mendes que:

De acordo com o ordenamento constitucional, não é razoável a manutenção do poder concedente de cada município participante, a meu ver, sob pena de esvaziar o conteúdo do artigo 25, parágrafo 3 da CF e a própria instituição da região metropolitana, microrregião ou aglomeração urbana. Além de inviabilizar a prestação integrada e o adequado atendimento de interesse comum.

Para ele, a inadequação da prestação da função de saneamento básico em um único município pode inviabilizar todo o esforço coletivo e afetar vários municípios próximos. Ele defende que: "O interesse comum é muito mais que a soma de cada interesse local envolvido, pois a má condição da função de saneamento básico por apenas um município pode colocar em risco todo o esforço do conjunto, além das consequências para a saúde pública de toda a região".

\footnotetext{
${ }^{3}$ A ADI foi ajuizada pelo Partido Democrático Trabalhista (PDT) contra leis que tratam da criação da região metropolitana e da microrregião dos Lagos no Estado do Rio (Lei Complementar n. 87/89) e sobre prestação de serviço de saneamento básico (Lei estadual n. 2.869/97).
} 
O entendimento do ministro Gilmar Mendes vai totalmente ao encontro da lógica por trás das funções públicas de interesse comum.

Ele aponta que a solução passaria pela ideia de que o agrupamento de municípios junto com o estado federado deteria a titularidade e o poder concedente, ou seja, caberia a um colegiado formado pelos municípios mais o estado federado decidir como integrar e atender adequadamente a função pública de interesse comum. O ministro acredita que:

[...] a região metropolitana deve, como ente colegiado, planejar, executar e funcionar como poder concedente dos serviços de saneamento básico, inclusive por meio de agência reguladora se for o caso, de sorte a atender ao interesse comum e à autonomia municipal.

Eis que, aquilo que o ministro Gilmar Mendes preconiza está bem desenhado no novo modelo de gestão metropolitana mineiro, anteriormente exposto, em que há representação dos munícipes no Conselho Deliberativo de Desenvolvimento Metropolitano. Órgão que pauta, em grande medida, as ações e projetos a serem executados pela Agência de Desenvolvimento da respectiva região metropolitana no que se refere às funções públicas de interesse comum. Ao passo que a Lei Complementar Fluminense n. 133, de 15 de dezembro de 2009, alterou a redação da Lei Complementar n. 87/1997, objeto da ADI n. 1.842. Com as alterações, o Conselho Deliberativo da Região Metropolitana do Rio de Janeiro (RMRJ) passou a ter representação de representante dos 19 municípios integrantes da RMRJ.

Para o ministro, essa participação dos municípios e do estado em órgão colegiado não seria necessariamente paritária, "desde que apta a prevenir a concentração de poder decisório no âmbito de um único ente". Ele defende que a participação desses entes deve ser estipulada por região metropolitana de acordo com suas particularidades, sem permitir predomínio absoluto de um ente.

Fundamentando-se na argumentação acima, o ministro Gilmar Mendes considera inconstitucional todos dispositivos que condicionam a execução da integração metropolitana ao exclusivo crivo de autoridade estadual.

Gilmar Mendes concluiu que a titularidade do serviço de saneamento básico relativamente à distribuição de água e coleta de esgoto é qualificada por interesse comum e deve ser concentrada na região metropolitana e na microrregião, conforme o artigo 25 , parágrafo 3ㅇ da CR/88, "respeitando a condução de seu planejamento e execução por decisões colegiadas dos municípios envolvidos e do estado do Rio de Janeiro".

Por fim, destacou que esta é uma questão extremamente delicada do aspecto de vista das consequências da declaração de inconstitucionalidade. Por essa razão suscitou a aplicação do artigo 27, da Lei Federal n. 9.868, de 10 de novembro de 1999, que dispõe sobre o processo e julgamento da ação direta de inconstitucionalidade e da ação declaratória de constitucionalidade perante o Supremo Tribunal Federal, de seguinte redação:

Art. 27. Ao declarar a inconstitucionalidade de lei ou ato normativo, e tendo em vista razões de segurança jurídica ou de excepcional interesse social, poderá o Supremo Tribunal Federal, por maioria de dois terços de seus membros, restringir os efeitos daquela declaração ou decidir que ela só tenha eficácia a partir de seu trânsito em julgado ou de outro momento que venha a ser fixado.

Dessa sorte, concede ao estado do Rio de Janeiro 24 meses, a contar da data da conclusão deste julgamento, para implementar o novo modelo de planejamento e execução da função do 
interesse comum no âmbito das regiões metropolitanas, microrregiões e aglomerados urbanos, acolhendo a participação dos municípios integrantes sem que haja concentração de poderes decisórios nas mãos de qualquer ente.

A Região Metropolitana de Belo Horizonte tem um tratamento especial no tocante à legislação sobre região metropolitana. Pode-se observar que houve recentemente uma retomada da temática metropolitana, com a proposição de um novo arranjo de gestão metropolitana. Destarte, a Emenda Constitucional Mineira n. 65 de 25 de novembro de 2004 trouxe significativas alterações na Constituição do Estado de Minas Gerais (CEMG).

Em seu art. 46, a CEMG (MINAS GERAIS, 1989) passou a ter a seguinte redação:

Art. 46- Haverá em cada região metropolitana:

I- uma Assembléia Metropolitana;

II- um Conselho Deliberativo de Desenvolvimento Metropolitano;

III- uma Agência de Desenvolvimento, com caráter técnico e executivo;

IV- um Plano Diretor de Desenvolvimento Integrado;

V- um Fundo de Desenvolvimento Metropolitano.

Nesse novo arranjo, foram criados três órgãos de gestão metropolitana para cada região metropolitana - Assembleia Metropolitana, Conselho Deliberativo de Desenvolvimento Metropolitano e Agência de Desenvolvimento - e dois instrumentos de planejamento - o Plano Diretor de Desenvolvimento Integrado (PDDI) e o Fundo de Desenvolvimento Metropolitano (FDM). Sendo que haverá um PDDI para cada região metropolitana e o FDM é comum a ambas as regiões metropolitanas mineiras.

Notadamente, a Assembleia Metropolitana constitui o órgão colegiado de decisão superior, com representantes do Estado e dos municípios metropolitanos. Compete principalmente à Assembleia definir as macrodiretrizes do planejamento global da região metropolitana. Já o Conselho Deliberativo de Desenvolvimento Metropolitano (CDDM) também é órgão colegiado da região metropolitana, mas com caráter mais técnico e representação da sociedade civil. Cabe ao CDDM deliberar sobre o planejamento e a execução das funções públicas de interesse comum; elaborar a programação normativa da implantação e da execução das funções públicas de interesse comum; provocar a elaboração e aprovar o PDDI da região metropolitana; aprovar as regras de compatibilização entre o planejamento da região metropolitana e as políticas setoriais adotadas pelo poder público para a região; e deliberar sobre a gestão do Fundo de Desenvolvimento Metropolitano.

A despeito do modelo, Gouvêa (2005 apud CÉSAR, 2007) traz que, quando existe uma estrutura institucionalizada de gestão metropolitana, a distribuição de atribuições administrativas e alocação de recursos financeiros podem não ser muito bem definidas. Isso porque as competências dos organismos metropolitanos normalmente não são exclusivas, mas compartilhadas com outros órgãos dos governos regionais e locais, o que acaba gerando certo grau de conflito entre instâncias e agências governamentais que atuam no território metropolitano, principalmente no tocante às FPICs.

Mais especificamente sobre as FPICs, em Minas, o caput do art. 43 da CEMG traz sua definição legal, nos seguintes termos: 
Art. 43- Considera-se função pública de interesse comum a atividade ou o serviço cuja realização por parte de um Município, isoladamente, seja inviável ou cause impacto nos outros Municípios integrantes da região metropolitana.

$\S 1$ a - A gestão de função pública de interesse comum será unificada.

$\S 2$ a - As especificações das funções públicas de interesse comum serão definidas na lei complementar que instituir região metropolitana, aglomeração urbana e microrregião.

A legislação complementar acima mencionada se deu através da Lei Complementar n. 89, que dispõe sobre a Região Metropolitana de Belo Horizonte, de 12 de janeiro de 2006. Define as FPIC em seu art. 8o da seguinte forma:

Art. 8o A atuação dos órgãos de gestão da RMBH (ou RMVA) abrangerá:

I- no transporte intermunicipal, [...];

II- no sistema viário de âmbito metropolitano, [...];

III- as funções relacionadas com a defesa contra sinistro e a defesa civil;

IV- no saneamento básico [...];

V- no uso do solo metropolitano, [...];

VI- no aproveitamento dos recursos hídricos, [...];

VII- na distribuição de gás canalizado, [...];

VIII- na cartografia e informações básicas, [...];

IX- na preservação e proteção do meio ambiente e no combate à poluição, [...];

X- na habitação, [...];

XI- no sistema de saúde, [...];

XII - no desenvolvimento socioeconômico, as funções públicas estabelecidas nos planos, programas e projetos contidos no Plano Diretor de Desenvolvimento Integrado. [...] (grifos nossos).

Como a Carta Magna não definiu expressamente nem elencou quais seriam as funções públicas de interesse comum, tal conceituação e classificação são feitas pelos estados, em suas constituições e legislação complementar. Abaixo, pode-se perceber distinta enumeração dada pelo Estado do Rio de Janeiro, pela Lei Complementar n. 87, de 16 de dezembro de 1997:

Art. 3o- Consideram-se de interesse metropolitano ou comum as funções públicas e os serviços que atendam a mais de um município, assim como os que, restritos ao território de um deles, sejam de algum modo dependentes, concorrentes, confluentes ou integrados de funções públicas, bem como os serviços supramunicipais, notadamente:

I - planejamento integrado do desenvolvimento econômico e social da Região Metropolitana do Rio de Janeiro ou comum às microrregiões e aglomerações urbanas, compreendendo a definição de sua política de desenvolvimento e fixação das respectivas diretrizes estratégicas e de programas, atividades, obras e projetos, incluindo a localização e expansão de empreendimentos industriais;

II - saneamento básico, incluindo o abastecimento e produção de água desde sua captação bruta dos mananciais existentes no Estado, inclusive subsolo, sua adução, tratamento e 
preservação, a distribuição de água de forma adequada ao consumidor final, o esgotamento sanitário e a coleta de resíduos sólidos e líquidos por meio de canais, tubos ou outros tipos de condutos e o transporte das águas servidas e denominadas esgotamento, envolvendo seu tratamento e decantação em lagoas para posterior devolução ao meio ambiente em cursos d'água, lagos, baías e mar, bem como as soluções alternativas para os sistemas de esgotamento sanitário;

III - transporte coletivo rodoviário, aquaviário, ferroviário e metroviário, de âmbito metropolitano ou comum, através de uma ou mais linhas ou percursos, incluindo a programação de rede viária, do tráfego e dos terminais de passageiros e carga; IV - distribuição de gás canalizado;

V-aproveitamento, proteção e utilização racional e integrada dos recursos hídricos, incluindo o transporte aquaviário, e o controle da poluição e preservação ambiental, com vistas ao desenvolvimento sustentável;

VI - cartografia e informações básicas para o planejamento metropolitano; e VII- habitação e disciplina do uso do solo. (RIO DE JANEIRO, 1997, grifos nossos).

Já no Estado de São Paulo, cabe aos Conselhos de Desenvolvimento das regiões metropolitanas paulistas definirem quais são as funções públicas de interesse comum da respectiva região metropolitana. É o que está estabelecido no art. 5ㅇ da Lei Complementar n. 815, de 30 de julho de 1996:

Artigo 5o- As funções públicas de interesse comum serão definidas pelo Conselho de Desenvolvimento da Região Metropolitana da Baixada Santista, entre os seguintes campos funcionais:

I- planejamento e uso do solo;

II- transporte e sistema viário regional;

III- habitação;

IV- saneamento básico,

V- meio ambiente;

VI- desenvolvimento econômico; e

VII- atendimento social. (SÃO PAULO, 1996, grifos nossos).

Observa-se que as FPICs em São Paulo não fogem muito do que é estabelecido em Minas e Rio, exceto pela inclusão da função pública de atendimento social. Isso porque as funções que causam impacto em municípios limítrofes da região metropolitana em geral são as mesmas em praticamente todas as metrópoles brasileiras.

\section{CONSIDERAÇÕES FINAIS}

Considerado o sistema federativo brasileiro e a legislação constitucional relacionada à questão metropolitana acima apresentada, pode-se aludir que o fato de um município pertencer a uma região metropolitana, apesar dos inúmeros benefícios decorrentes dessa adesão, também representa significativa e potencial amarra à autonomia municipal em diversas situações. Amarras essencialmente, as relacionadas às FPICs, que por sua vez tendem a ser regulamentadas por leis estaduais enquanto atribuição da metrópole, e não apenas de um município isoladamente. 
Isto porque, como aqui aprofundado, o município por si só na maioria das vezes não consegue administrar de forma eficiente e racional a execução dessas FPICs.

Ao que se constatou, por haver latentes conflitos de competências constitucionais sobre determinadas funções entre os entes federativos, a discussão atualmente permeia inclusive o Supremo Tribunal Federal. Por mais que o arcabouço legal, em âmbito constitucional ou infraconstitucional inclusive municipal, atribua tais funções públicas aos municípios, roborando sua autonomia, até nossa corte suprema já reconhece a necessidade de uma instância metropolitana participativa, sem, contudo, traduzir-se a instância metropolitana num quarto ente federado, inexistente em nosso ordenamento jurídico atual.

Imperioso apontar os avanços trazidos pelo Estatuto da Metrópole, que inovou em nosso ordenamento jurídico com regras específicas e diretrizes para o planejamento, a gestão e a execução das funções públicas de interesse comum em regiões metropolitanas e em aglomerações urbanas instituídas pelos Estados. O Estatuto ainda cuidou de normas gerais sobre o plano de desenvolvimento urbano integrado e outros instrumentos de governança interfederativa, além de aduzir critérios para o apoio da União a ações que envolvam governança interfederativa no campo do desenvolvimento urbano.

Com as mudanças promovidas, relativas à nova estruturação metropolitana, impõe-se aos entes federativos a necessidade de se adequarem ao novo arranjo. Em certa medida, tanto a administração pública estadual como as municipais geralmente são estruturadas tematicamente. Destarte, tem-se determinada política pública específica, como saúde, educação, transporte, habitação etc., e sua correspondente secretaria - de saúde, de educação, de transporte, de habitação etc. - em âmbito municipal ou estadual.

Nesse desiderato, revela-se mais racional e eficiente se as administrações públicas municipais e estaduais adequassem não apenas suas legislações, mas que promovessem inclusive ações em conjunto relacionadas às FPICs, de preferência com interveniência do Estado, visando à melhoria na alocação dos recursos públicos, galgando maior eficiência para as administrações públicas nacionais.

Vale frisar mais uma vez, que o objetivo pretendido é o princípio da eficiência contemplado em nossa Carta Magna, em seu art. 37 caput. E tal eficiência na execução das funções públicas de interesse comum pode ser alcançada por vários meios de gestão compartilhada entre os entes, seja com mudanças na legislação estadual e dos municípios, seja por consórcios públicos, convênios ou outras formas de pactuação.

Grosso modo, pode-se defender que, através da governança metropolitana, é mais provável a obtenção de bem-estar sistêmico. Isso, visto que o apoio e a indução da gestão associada de serviços entre os municípios, visando à obtenção de ganhos de escala e o aumento de oferta de serviços públicos, acabam por beneficiar inclusive, aquelas parcelas da população antes privada de tais serviços.

No final das contas, no tema em tela, independentemente da titularidade da competência sobre determinada função pública, o grande desafio para o gestor continua sendo coadunar as ferramentas gerenciais trazidas pela legislação administrativa às administrações públicas municipais e estaduais. 


\section{REFERÊNCIAS}

BARROSO, Luís Roberto. Saneamento básico: competências constitucionais da União, Estados e Municípios. REDAE - Revista Eletrônica de Direito Administrativo Econômico, n. 11, out. 2007. Disponível em: <http:// www.direitodoestado.com/revista/REDAE-11-AGOSTO-2007-LUIS\%20ROBERTO\%20BARROSO.pdf>AcesSO em: 10 nov. 2015.

BRASIL. Lei n. 13.089, de 12 de janeiro de 2015. Institui o Estatuto da Metrópole, altera a Lei ㄲo 10.257, de 10 de julho de 2001, e dá outras providências. Disponível em: <http://www.planalto.gov.br> Acesso em: 10 jun. 2016.

. Lei no 9.868, de 10 de novembro de 1999. Dispõe sobre o processo e julgamento da ação direta de inconstitucionalidade e da ação declaratória de constitucionalidade perante o Supremo Tribunal Federal. Brasília, DF: Presidência da República, 1999. Disponível em: <http://www.planalto.gov.br/ccivil_03/leis/ L9868.htm>. Acesso em: 25 jan. 2016.

Supremo Tribunal Federal. Jurisprudência: Ação Direta de Inconstitucionalidade no 1.842. Disponível em: 1998. <http://www.stf.jus.br/portal/processo/verProcessoDeslocamento.asp?incidente=1714588> Acesso em: 21 fev. 2016.

Supremo Tribunal Federal. Jurisprudência: Ação Direta de Inconstitucionalidade no 2.077-3. Disponível em: <http://www.stf.jus.br/imprensa/pdf/ADI2077ErosGrau.pdf> Acesso em: 01 nov. 2015.

. Constituição da República Federativa do Brasil (1988). Brasília, DF: Congresso Nacional, 1988.

. Lei Complementar no 14, de 8 de junho de 1973. Estabelece as regiões metropolitanas de São Paulo, Belo Horizonte, Porto Alegre, Recife, Salvador, Curitiba, Belém e Fortaleza. Brasília, DF: Presidência da República. Disponível em: <http://www4.planalto.gov.br/legislacao/legislacao-1/leis-complementares-1/ leis-complementares-1/1973\#content>. Acesso em: 15 dez. 2015.

. Constituição da República Federativa do Brasil (1967). Brasília, 24 de janeiro de 1967.

Constituição dos Estados Unidos do Brasil (1937). Rio de Janeiro, 10 de novembro de 1937.

CÉSAR, Paulo Sérgio Mendes. A Agência de Desenvolvimento Metropolitano da Região Metropolitana de Belo Horizonte. 2007. 109p. Monografia (Especialização em Direito Público) - Fundação João Pinheiro CSAP, Belo Horizonte, 2007.

. Consórcios Públicos e o Princípio da Eficiência na Administração Pública. 2008. Monografia (Curso de Direito) - Universidade Federal de Minas Gerais (UFMG), Belo Horizonte, MG, 2008.

FERNANDES, Edésio; PEREIRA, Helena Dolabela. O direito à continuidade das políticas públicas. Fórum de Direito Urbano e Ambiental, Belo Horizonte, v. 8, n. 48, nov. 2009. Disponível em: <http://bdjur.stj.jus. br/dspace/handle/2011/29386>. Acesso em: 3 dez. 2015.

FREITAS, Paulo Springer de. A Regulamentação do Artigo 23 da Constituição Federal. Brasília: Senado, 2008. Disponível em: <http://www12.senado.gov.br/ publicacoes/estudos-legislativos/tipos-de-estudos/ outras-publicacoes/volume-ii-constituicao-de-1988-o-brasil-20-anos-depois.-o-exercicio-da-politica/aregulamentacao-do-artigo-23-da-constituicao-federal>. Acesso em: 6 abr. 2016.

GRAU, Eros Roberto. Regiões metropolitanas: regime jurídico. São Paulo: José Bushatsky, 1974.

GUIA, Virginia Rennó dos Mares. Estudos Básicos para a RMBH: subsídios para o plano de desenvolvimento. Tema Transversal - Gestão Metropolitana. Belo Horizonte: Fundação João Pinheiro, 2006.

GUIMARÃES, Tatiana Cordeiro. O consórcio público como instrumento de fortalecimento do federalismo brasileiro - marco legal, vantagens e condições de formação. 2010. Dissertação (Mestrado em Administração Pública) - Fundação João Pinheiro, Belo Horizonte, MG, 2010.

HENRIQUES FILHO, Tarcísio. Regiões metropolitanas e autonomia dos municípios. RDA - Revista de Direito Administrativo, Rio de Janeiro, v. 264, p. 214-239, set./dez. 2006.

HORTA, Raul Machado. Direito Constitucional Brasileiro e as regiões metropolitanas. Revista de Informação Legislativa, Brasília, v. 12, n. 46, p. 33-42, abr./jun. 1975. Disponível em: <http://www2.senado.leg.br/ bdsf/bitstream/handle/id/182005/000867054.pdf?sequence=1>. Acesso em: 1으 maio 2016. 
LUSTOSA, Elisa Versiani. A governança metropolitana e seus desafios: uma análise do primeiro ano de funcionamento da Agência da RMBH. 2010. 102p. Monografia (Graduação em Administração Pública) Fundação João Pinheiro, CSAP, Belo Horizonte, 2010.

MACHADO, Gustavo G.; SOUKI, Lea G.; FARIA, Carlos A. P. Processo legislativo, articulação intergovernamental e gestão metropolitana: inovação institucional e participação social na Região Metropolitana de Belo Horizonte. In: CONGRESSO BRASILEIRO DE SOCIOLOGIA, GT 02: Cidades e processos sociais, XIII, 2007, Recife. Resumos... Recife: SBS, 2007. v. 1, p. 67.

MEIRELLES, Hely Lopes. Direito Municipal Brasileiro. 6. ed. São Paulo: Malheiros, 1993.

MELLO, Celso Antônio Bandeira de. Curso de Direito Administrativo. 11. ed. São Paulo: Malheiros, 1999.

MINAS GERAIS, Estado [de]. Decreto no 45.083, de 3 de abril de 2009. Contém o regulamento da Agência de Desenvolvimento da Região Metropolitana de Belo Horizonte e dá outras providências. Belo Horizonte: Assembleia Legislativa do Estado de Minas Gerais. Disponível em: <http://www.almg.gov.br>. Acesso em: 22 dez. 2015.

. Lei Complementar no 89, de 12 de janeiro de 2006. Dispões sobre a Região Metropolitana de Belo Horizonte. Belo Horizonte: Assembleia Legislativa do Estado de Minas Gerais. Disponível em: <http:// www.almg.gov.br>. Acesso em: 11 jan. 2016.

Emenda à Constituição [do Estado] no 65, de 25 de novembro de 2004. Altera os artigos 42 a 50 da Constituição do Estado. Belo Horizonte: Assembleia Legislativa do Estado de Minas Gerais, 2004. Disponível em: <http://www.almg.gov.br>. Acesso em: 19 dez. 2015.

Constituição do Estado de Minas Gerais. Belo Horizonte: Assembleia Legislativa do Estado de Minas Gerais, 1989. Disponível em: <http://www.almg.gov.br>. Acesso em: 1o set. 2015.

MOREIRA, Danielle de Andrade; GUIMARÃES, Virgínia Totti. Regiões metropolitanas e funções públicas de interesse comum: o ordenamento territorial diante do Estatuto da Metrópole. Revista de Direito da Cidade, Rio de Janeiro, v. 7, n. 3, p. 1249-1269, 2015.

OLIVEIRA, Fabrício Augusto de. Teorias da Federação e do Federalismo Fiscal: o caso brasileiro. Belo Horizonte: FJP, 2007.

RIO DE JANEIRO, Cidade [de]. Lei Complementar no 133, de 15 de dezembro de 2009. Altera a lei complementar no 87, de 16 de dezembro de 1997, com a nova redação dada pela lei complementar no 97, de 2 de outubro de 2001, a lei complementar no 89, de 17 de julho de 1998, a lei complementar no 105, de 4 de julho de 2002, e a lei complementar no 130, de 21 de outubro de 2009, e dá outras providências, na forma que menciona.

Lei Complementar no 87, de 16 de dezembro de 1997. Dispõe sobre a Região Metropolitana do Rio de Janeiro, sua composição, organização e gestão, e sobre a Microrregião dos Lagos, define as funções públicas e serviços de interesse comum e dá outras providências.

. Lei no 2.869, de 18 de dezembro de 1997. Dispõe sobre o regime de prestação do serviço público de transporte ferroviário e metroviário de passageiros no estado do Rio de Janeiro, e sobre o serviço público de saneamento básico no estado do Rio de Janeiro, e dá outras providências.

SABOIA, Marcelo Rocha. Notas sobre as regiões metropolitanas. Revista de Informação Legislativa, Brasília, v. 35, n. 138, p. 231-236, abr./jun. 1998.

SANTOS, Gabriella Marques de Azevedo dos. As competências e formas de execução dos serviços públicos. 2007. Disponível em: <http://academico.direito-rio.fgv.br/ccmw/Gabriella_Marques_de_Azevedo_dos_ Santos_-_Aula_4_2007.2>. Acesso em: 14 out. 2015.

SÃO PAULO, Cidade [de]. Lei Complementar no 815, de 30 de julho de 1996. Cria a Região Metropolitana da Baixada Santista e autoriza o Poder Executivo a instituir o Conselho de Desenvolvimento da Região Metropolitana da Baixada Santista, a criar entidade autárquica e a instituir o Fundo de Desenvolvimento Metropolitano da Baixada Santista. 
. Lei Complementar no 760, de 1을 de agosto de 1994. Estabelece diretrizes para a Organização Regional do Estado.

SILVA, José Afonso da. Curso de Direito Constitucional Positivo. São Paulo: Malheiros, 2004. 418p.

SOUZA, José Moreira de. Aspectos institucionais da região metropolitana de Belo Horizonte. Plano estratégico da Grande BH (painéis). Belo Horizonte: Instituto Horizontes, 2002.

TEMER, Michel. Elementos de Direito Constitucional. 14. ed. São Paulo: Malheiros, 1998.

\section{Sobre o autor:}

Paulo Sérgio Mendes César: Doutorando em Ciência Política pela Universidade Federal de Minas Gerais (UFMG), mestre em Administração Pública pela Fundação João Pinheiro, especializado em Direito Público pela Universidade Católica Dom Bosco (UCDB), Graduado em Direito pela UFMG e em Administração Pública pela Escola de Governo da Fundação João Pinheiro. Advogado, servidor público estadual da carreira Especialista em Políticas Públicas e Gestão Governamental em Minas Gerais. E-mail: paulo_smendes@yahoo.com.br 
